\title{
Inquietudes de duas pesquisadoras quanto às reflexões de profissionais da Educação Infantil diante das relações étnico-raciais e o preconceito face aos imigrantes
}

\begin{abstract}
Resumo:
Os pressupostos apresentados neste estudo são recorte de uma pesquisa em desenvolvimento num Programa de Pós-Graduação em Educação e tem como base a Sociologia da Infância, a educação para as relações étnico-raciais e o preconceito face aos imigrantes diante da construção social. A coleta de dados foi realizada utilizando questionário com profissionais da Educação Infantil da Prefeitura Municipal de Florianópolis via e-mail e conversas via aplicativo de mensagem. Procurou-se, diante das respostas dos profissionais, refletir sobre posturas sociais naturalizadas no cotidiano das instituições educativas e com isso, sobre as formas como tais práticas socioeducativas produzem e revelam as questões étnico-raciais de forma estrutural. Considerando um discurso ainda muito forte das imagens racialmente propagadas da branquitude e a compreensão da existência de privilégios diante da cor, esta pesquisa constitui mais um subsídio para reflexões diante destas relações étnico-raciais.
\end{abstract}

\section{Palavras-chave:}

Construção social. Educação Infantil. Imigrantes. Relações étnico-raciais. Sociologia da Infância.

\begin{abstract}
:
The assumptions presented in this study are part of a research study under development in a Graduate Program in Education and it is based on the Sociology of Childhood, the education for ethnicorracial issues and the prejudice against immigrants in the face of social construction. Data collection was carried out using a questionnaire with professionals in Early Childhood Education from the Municipality of Florianópolis via e-mail and conversations via messaging application. In view of the responses, we sought to reflect about naturalized social attitudes in the daily life of educational institutions and with this, about the ways in which these social educational practices produce and reveal the ethnicorracial issues in a structural manner. Considering a still very strong discourse of the racially propagated images of whiteness and the understanding of the existence of privileges in face of color, this study constitutes yet another subsidy for reflections in the face of these ethnicorracial relations.
\end{abstract}

\section{Keywords:}

Social construction. Early Childhood Education. Immigrants. Ethnicorracial relations. Sociology of Childhood.

\footnotetext{
* Mestranda em Educação, da linha de Linguagens, Arte e Educação, na Universidade Regional de Blumenau (FURB). Bolsista FUMDES/UNIEDU. Professora da Educação Infantil na Prefeitura Municipal de Florianópolis. E-mail: gisele.macaneiro@prof. pmf.sc.gov.br. ORCID iD: https://orcid.org/0000-0002-7530-2674.

** Doutora em Estudos da Linguagem pela Universidade Federal de Santa Catarina. Docente no curso de Letras e no Programa de Pós-Graduação em Educação da FURB. E-mail: cbailer@furb.br. ORCID iD: http://orcid.org/0000-0002-9049-8003.
} 


\section{Introdução}

O presente artigo trata de um recorte de uma pesquisa em andamento num Programa de Pós-Graduação em Educação que objetiva apresentar reflexões a partir de autores que discutem a educação infantil, as relações étnico-raciais e o preconceito face aos imigrantes e/ou filhos de imigrantes em instituições de Educação Infantil, bem como um levantamento de dados realizado por meio de um questionário que foi respondido por profissionais que atuam na rede pública no município de Florianópolis e atendem crianças haitianas e/ou filhos de imigrantes haitianos em suas salas de aula.

A rede pública municipal de Florianópolis é composta, segundo dados oficiais ${ }^{1}$, por oitenta e nove Núcleos de Educação Infantil Municipais (NEIMs) com atendimento em período integral e parcial. Os NEIMs atendem crianças com idade a partir de 4 meses até 3 anos, 11 meses e 29 dias em creche e crianças de 4 anos a 5 anos, 11 meses e 29 dias em pré-escolar.

Conforme dados da Diretoria de Educação Infantil relatados pela Gerência de Formação Continuada da Prefeitura Municipal de Florianópolis (PMF) às pesquisadoras, o número total de crianças haitianas e/ou filhos de imigrantes haitianos matriculados em 2020 na Educação Infantil é de 56 no total. Ao evidenciar o número total de crianças haitianas e/ou filhos de imigrantes haitianos matriculados na educação infantil de Florianópolis, salienta-se a demanda, tornando, assim, relevante a reflexão sobre o acolhimento a essas crianças e a suas famílias. É preciso garantir a esses pequenos condições educacionais que almejem seu desenvolvimento integral, valorizando sua cultura e fortalecendo suas subjetividades como toda criança merece e tem o direito.

Para compreender como os haitianos chegaram a Florianópolis, é preciso trazer um pouco de sua história. Assim, Magalhães (2015) relata que o Haiti é um país historicamente marcado por emigração forçada devido às suas dificuldades históricas e sociais desde sua colonização. Mesmo após sua independência, o Haiti continuou a se submeter ao cerceamento dos colonizadores. O sofrimento de sua população e o recomeço constante diante de calamidades fizeram deste povo sinônimo de força e resistência, suas principais características para a sobrevivência.

Desde sua independência, a população haitiana vive uma profunda crise econômica e social. O terremoto devastador de janeiro de 2010, conforme evidenciam Alphonse e Macedo (2017), dificultou ainda mais a permanência da população, pois assolou o país definitivamente. Milhares de pessoas morreram e milhões ficaram desabrigados. Foram muitas as promessas de ajuda humanitária para a reconstrução do país, no entanto, atualmente a população haitiana ainda vivencia a situação de um país em profunda crise, um dos mais pobres da América Latina.

Em 2010, ainda conforme destacam Fernandes, Castro e Ribeiro (2014), o Haiti foi atingido por um surto de cólera que matou mais de oito mil pessoas e em 2012 foi novamente afetado por dois furacões. As situações históricas, econômicas e sociais adversas a este país resultaram na saída de haitianos de sua terra natal. Porém, após esses desastres naturais o fluxo emigratório foi ainda maior e uma expressiva parcela da população precisou buscar melhores condições de vida e sobrevivência em outros países. Dessa forma, o Brasil foi um desses destinos escolhidos pelos haitianos.

Estima-se que até o final do ano de 2016, conforme Magalhães e Baeninger (2016), cerca de oitenta mil haitianos tenham vindo ao Brasil, chegando primeiramente pelo norte do país. No Acre, esses imigrantes eram contatados por empresas para trabalhar nas mais diversas regiões do país. Empresas do Vale do Itajaí (Multilog, Ambiental e Embrasul), no estado de Santa Catarina, foram até cidades fronteiriças do Acre para recrutar imigrantes para funções mais pesadas de trabalho com menos qualificação em 2011. Após, os haitianos se espalharam por todo estado principalmente para o Oeste em empresas frigoríficas e para a grande Florianópolis devido à contratação na alta temporada de verão, já que Florianópolis é uma capital turística e apresenta uma grande demanda de trabalho na construção civil. Magalhães (2015)

1. Informações retiradas do site da Prefeitura Municipal de Florianópolis. Disponível em: http://www.pmf.sc.gov.br/entidades/educa/ index.php?cms=diretoria+de+educacao+infantil+++dei\&menu=9\&submenuid=254. Acesso em: 16 set. 2020. 
destaca em sua pesquisa o preconceito e a exploração desses imigrantes diante dos nativos, em situações nas quais os trabalhos penosos e insalubres sempre permaneciam com eles, com remunerações menores, sem possibilidades de crescimento, habitando locais em situações precárias e recebendo descontos em seus salários. Em nossa interpretação, tais características parecem revelar a submissão destes a condições análogas à escravidão moderna.

Com este público de trabalhadores haitianos imigrantes residentes na capital catarinense, percebe-se com estas famílias uma nova realidade nas instituições de educação infantil, os filhos desses imigrantes, tornando-se então de extrema relevância que a secretaria de educação, as instituições de educação infantil e seus profissionais capacitem-se, reflitam e coloquem em prática o documento para a Educação para as Relações Étnico-Raciais (ERER) (PMF, 2016). Esse documento da rede é de suma importância para uma prática educativa pautada no respeito e na valorização da diversidade diante das raças e etnias tão presentes em uma população miscigenada como a brasileira, que só se faz ampliar com a chegada desses imigrantes.

Considerando que a geração de dados para a pesquisa de campo estava prevista para acontecer a partir de março de 2020 em unidades de Educação Infantil numa perspectiva etnográfica, com as pesquisadoras inseridas no cotidiano educativo com as profissionais, crianças e famílias, com a utilização de instrumentos como a observação participante, entrevistas, fotos, vídeos e diário de campo, a pandemia causada pelo coronavírus SARS-CoV-2 afetou a ida a campo. Instituições de ensino tiveram que suspender as aulas presenciais nas unidades de ensino de Santa Catarina pelo Decreto Estadual n 509 (SANTA CATARINA, 2020a) e continuam suspensas, pelo menos até 7 de setembro, pelo Decreto Estadual n ${ }^{\circ} 724$ (SANTA CATARINA, 2020b). Dessa forma, foi necessário adaptar os objetivos e instrumentos da pesquisa.

A partir do contato com cinco instituições de ensino da rede municipal de Florianópolis via e-mail e aplicativo de mensagens, a apresentação da pesquisa aos potenciais participantes foi feita em transmissão síncrona com as unidades e também via comunicação entre a direção das unidades e as profissionais. A solução mais viável e possível para o momento de distanciamento físico foi o envio de questionários por e-mail às profissionais, já que por questões sociais adversas as famílias e crianças não puderam participar da pesquisa por não possuírem acesso à internet e equipamentos tecnológicos. A falta da interação presencial com o campo de pesquisa e com as profissionais envolvidas impactou, inicialmente, as pesquisadoras, porém o retorno dos questionários respondidos foi nos motivando a prosseguir e revelando que as reflexões sobre a temática estão longe de serem conclusivas.

Pensar as relações étnico-raciais na Educação Infantil partindo do pressuposto da inclusão, valorização, formação, quebra de padrão e de estereótipos, a compreensão do etnocentrismo diante da história e ainda concebido, torna-se estudo de relevância urgente para a Educação. Provocar reflexões diante do estudo da história e da cultura afro-brasileira e das práticas na educação se fazem emergentes, principalmente em ambientes educativos com tanta diversidade cultural, étnica e racial em um mesmo ambiente, principalmente diante da inclusão de muitas crianças negras e imigrantes haitianas e/ou filhas de imigrantes haitianos nas instituições de Educação Infantil de Florianópolis.

Este artigo procura discutir, a partir das respostas das profissionais de educação, refletir sobre posturas sociais naturalizadas no cotidiano das instituições de Educação Infantil e com isso, sobre as formas como tais práticas socioeducativas produzem e revelam as questões étnico-raciais de forma estrutural. Desta forma, estudos acerca das relações étnico-raciais nas instituições educativas se fazem primordiais, considerando que só a Educação pode transformar, mesmo tendo em vista que "a transformação da educação não pode antecipar-se à transformação da sociedade, mas esta transformação necessita da educação" (FREIRE, 1991, p. 84). 


\title{
As relações étnico-raciais na infância: resultado de interações sociais
}

\begin{abstract}
"Ninguém nasce odiando outra pessoa pela cor de sua pele, por sua origem ou ainda por sua religião. Para odiar, as pessoas precisam aprender, e se podem aprender a odiar, elas podem ser ensinadas a amar."
\end{abstract}

Nelson Mandela

A partir deste pequeno trecho do grande líder negro Nelson Mandela, referência na luta contra o apartheid, iniciamos nossa reflexão diante do racismo arraigado em nossa sociedade. Tomando como princípio que não se nasce odiando o nosso semelhante, mas que se aprende com as relações sociais estabelecidas desde a mais tenra idade, desta forma, é preciso refletir se a Educação Infantil tem proporcionado às nossas crianças práticas pedagógicas que privilegiam e valorizam as diferenças ou se tem perpetuado as relações étnico-raciais em conflito?

Este artigo não objetiva trazer conclusões, mas proporcionar reflexões acerca de posturas pedagógicas na Educação Infantil diante da Lei de Diretrizes e Bases da Educação Nacional (BRASIL, 1996), modificada pela Lei $n^{\circ} 11.645$,

Art. 26-A. Nos estabelecimentos de ensino fundamental e de ensino médio, públicos e privados, torna-se obrigatório o estudo da história e cultura afro-brasileira e indígena.

$\$ 1^{\circ} \mathrm{O}$ conteúdo programático a que se refere este artigo incluirá diversos aspectos da história e da cultura que caracterizam a formação da população brasileira, a partir desses dois grupos étnicos, tais como o estudo da história da África e dos africanos, a luta dos negros e dos povos indígenas no Brasil, a cultura negra e indígena brasileira e o negro e o índio na formação da sociedade nacional, resgatando as suas contribuições nas áreas social, econômica e política, pertinentes à história do Brasil.

Constata-se que a Educação Infantil não está comtemplada neste artigo, porém pensar nesta como parte integrante da Educação Básica é ir além e se imbuir dos demais documentos orientadores como as Diretrizes Curriculares Nacionais, os Parâmetros Curriculares Nacionais, a Base Nacional Comum Curricular e os documentos municipais como da própria Prefeitura Municipal de Florianópolis (PMF) diante da matriz curricular para a Educação para as Relações Étnico-Raciais (ERER). Discutir esses documentos com profissionais da Educação Infantil é formá-los para práticas pedagógicas a uma educação pautada para as relações étnico-raciais sob perspectivas que problematizem posturas de embranquecimento e etnocentrismo.

Conforme Carvalho (1997, p. 181), “[o] etnocentrismo consiste em privilegiar um universo de representações propondo-o como modelo e reduzindo à insignificância dos demais universos e culturas diferentes". É, portanto, relevante ao profissional de Educação promover práticas que vão ao encontro do diálogo da diversidade cultural, quebrando com a naturalização do etnocentrismo frequentemente ainda presente em posturas e nas raízes das instituições educativas. $\mathrm{O}$ autor evidencia o etnocentrismo como uma violência histórica enraizada nas diversas formas de colonialismo, disfarçada na "violência simbólica", sendo que privilegia o padrão (do sujeito branco, heterossexual, masculino, nativo e de classe social abastada) e declara as outras culturas como subalternas, sendo "exorcizadas" por várias táticas. Assim, as instituições educativas atuam como um instrumento para a manutenção deste "colonialismo cognitivo" e para o apagamento de culturas não padrões.

Cabe ainda ressaltar que para imigrantes como os haitianos de "origem racial, étnica e econômica rechaçada pela cultura hegemônica - eurocêntrica, colonialista e racista -, a situação de desamparo do imigrante é ainda mais preocupante" (GOMES, 2017, p. 8). Neste sentido, faz-se necessário refletir sobre essas questões com profissionais que trabalham com as crianças haitianas e/ou filhas de imigrantes já que estas sofrem com esta discriminação se sobrepondo ainda de maneira interseccional, pois, segundo Gomes (2017), são crianças imigrantes e negras, ou seja, sofrem com duas formas de opressão que se intensificam. 
Desta forma, conforme Ribeiro (2017), evidencia-se que compreender a questão do embranquecimento como "vantagem" a uma mobilidade social é de extrema importância para educadores no tocante à reflexão e transformação deste status quo. Na sociedade, nas palavras de Ribeiro (2017, p. 2), os "não brancos e principalmente pretos sofrem desvantagens significativas em relação aos brancos". Fato arraigado no Brasil que se evidencia mesmo diante da desigualdade social em que a raça ainda prevalece nas chances de ascensão social. Raça, para Ribeiro (2017, p. 2), "é definida antes pela aparência do que pela origem, pessoas entre o polo mais claro (branco) e o polo mais escuro (preto) do contínuo de cor ou raça têm mais chances de experimentar fluidez classificatória”.

Diante dessas questões evidenciadas de forma naturalizada em uma sociedade racista, a presente pesquisa dialoga com a valorização da diversidade racial e cultural, tendo como propósito reunir reflexões de profissionais da educação infantil que tiveram a oportunidade de vivenciar práticas com crianças haitianas e/ou filhos de imigrantes haitianos.

Pensar na criança e na infância como ator social é compreender que ambas se desenvolvem diante da construção social e das representações historicamente construídas sobre e para elas. Nas palavras de Sarmento (2005, p. 363), "[a] infância é concebida como uma categoria social do tipo geracional por meio da qual se revelam as possibilidades e os constrangimentos da estrutura social". Conforme Pinto (1997), refletir as dimensões sociais da infância é compreender que a mesma é fruto de um conjunto de processos sociais, nos quais a infância surge como realidade social e espelho da própria sociedade.

A concepção de infância foi vista por muito tempo, segundo Pinto (1997), como o que falta para vir a ser e a fazer para se tornar adulto, ou ainda como iniciação ao mundo adulto, resultando na percepção da criança como um adulto em miniatura. Longe de ser somente uma etapa constituída por fatores biológicos, a construção moderna de infância contribuiu para a separação do mundo adulto, na valorização do que a criança já sabe fazer, no que a mesma já é em suas aptidões, assim como a proteção deste ciclo e a institucionalização das crianças via creches e escolas públicas. Sabe-se que este direito à educação pública principalmente na Educação Infantil ainda não atingiu acesso universal, mas como direito fica sempre a reflexão da necessidade de políticas públicas, pois a Educação Infantil desde a mais tenra idade é essencial para a socialização por meio da interação especializada com profissionais capacitados, ou seja, o professor pode contribuir muito para uma mudança significativa diante das relações de discriminação e preconceito desde muito cedo com nossos pequenos.

É preciso esclarecer que crianças são sujeitos em desenvolvimento e com especificidades de acordo com cada faixa etária. Nas palavras de Sarmento (2005, p. 370), “as crianças são também seres sociais e, como tais, distribuem-se pelos diversos modos de estratificação social: a classe social, a etnia a que pertencem, a raça, o gênero, a região do globo onde vivem. Os diferentes espaços estruturais diferenciam profundamente as crianças".

A Sociologia da Infância, conforme Sarmento (2005), denomina infância como a categoria social do tipo geracional e criança, o sujeito concreto que integra essa categoria geracional, um ator social que se desenvolve constantemente diante da interação com o meio e com os outros. Pensando no desenvolvimento infantil das crianças diante da interação, é fundamental pensar nos processos de mediação na Educação Infantil e ainda mais no que tange às relações étnico-raciais, considerando que o preconceito não nasce com o indivíduo, constitui-se diante das relações na sociedade em que vive.

Para Kramer (2007), a dificuldade de compreender que somos feitos de pluralidade e estabelecidos na diferença se traduz na realidade experienciada. Parece que a humanidade ainda não aprendeu a conviver com a heterogeneidade e assim educamos nossas crianças em um ambiente extremamente hostil, principalmente com aqueles que não se encaixam no padrão estabelecido diante do social, da raça, da cor, do gênero e da etnia. 


\section{Inquietudes deste estudo}

"Não existe revelação mais nítida da alma de uma sociedade do que a forma como esta trata as suas crianças."

Nelson Mandela

Pensar no desenvolvimento das crianças inseridas em uma sociedade racista é refletir como educador que as interações positivas contribuem para esta mudança. Pensar na criança como sujeito ativo na sociedade com suas subjetividades próprias dentre cultura, língua, raça, cor, posição social e etnia, exige considerá-las de forma a serem valorizadas e respeitadas. O respeito aos direitos das crianças, sejam quais forem suas características e pertencimento, é garantido, principalmente no artigo $3^{\circ}$ do Estatuto da Criança e do Adolescente, Lei no 8.069 (BRASIL, 1990, grifo nosso), modificado pela Lei no 13.257 :

Art. $3^{\circ} \mathrm{A}$ criança e o adolescente gozam de todos os direitos fundamentais inerentes à pessoa humana, sem prejuízo da proteção integral de que trata esta Lei, assegurando-se lhes, por lei ou por outros meios, todas as oportunidades e facilidades, a fim de lhes facultar o desenvolvimento físico, mental, moral, espiritual e social, em condições de liberdade e de dignidade.

[...] Parágrafo único. Os direitos enunciados nesta Lei aplicam-se a todas as crianças e adolescentes, sem discriminação de nascimento, situação familiar, idade, sexo, raça, etnia ou cor, religião ou crença, deficiência, condição pessoal de desenvolvimento e aprendizagem, condição econômica, ambiente social, região e local de moradia ou outra condição que diferencie as pessoas, as famílias ou a comunidade em que vivem.

É importante refletir se as instituições de ensino têm cumprido com seu objetivo de proteger e possibilitar o desenvolvimento integral das crianças garantindo a elas oportunidades para legitimar e valorizar seu pertencimento de raça, etnia, situação social, cor e cultura que cada um traz consigo. Acerca da questão cultural, é importante ressaltar que conhecer costumes e hábitos diversos que as crianças trazem consigo para o interior das instituições, principalmente referente à sua cultura é relevante para que possamos realizar um trabalho pedagógico de valorização e pertencimento.

A cor, raça e etnia são características pertencentes às crianças que estão nas instituições educativas, mas será que as diferenças são trabalhadas de modo a considerá-las como elementos importantes dentro de um país multirracial como o Brasil? Ou ainda seguimos naturalizando um posicionamento etnocêntrico e de embranquecimento em nossa sociedade?

Para esta reflexão, Gomes (2005b, p. 148) ressalta que “[o] entendimento conceptual sobre o que é racismo, discriminação racial e preconceito, poderia ajudar os(as) educadores(as) a compreenderem a especificidade do racismo brasileiro e auxiliá-los a identificar o que é uma prática racista e quando esta acontece no interior da escola". Assim, os posicionamentos e ações naturalizadas poderiam passar a ter entendimento de sua concepção em sociedade. Desta forma, o conhecimento geraria consciência que poderia se transformar em práticas pedagógicas mais conscientes e reflexivas.

Motta e Paula (2019) enfatizam que a sociedade é marcada pela imposição da cultura europeia do homem branco. Homem este que tem sido o modelo e padrão na sociedade desde a colonização do Brasil. Para Quijano (2005, p. 105),

[e]m outras palavras, raça e identidade racial foram estabelecidas como instrumentos de classificação social básica da população. Com o tempo, os colonizadores codificaram como cor os traços fenotípicos dos colonizados e a assumiram como a característica emblemática da categoria racial. [...] Em consequência, os dominantes chamaram a si mesmos de brancos. Na América, a ideia de raça foi uma maneira de outorgar legitimidade às relações de dominação impostas pela conquista. 
Nossas identidades foram e continuam sendo construídas no processo de socialização. Diante disto, propostas pedagógicas na educação infantil que visam um trabalho de conscientização do diferente como soma e de relevante valorização são urgentes. Neste sentido, Gomes (2005b, p. 147) ressalta que

[p]ara que a escola consiga avançar na relação entre saberes escolares/realidade social/diversidade étnico-cultural é preciso que os(as) educadores(as) compreendam que o processo educacional também é formado por dimensões como a ética, as diferentes identidades, a diversidade, a sexualidade, a cultura, as relações raciais, entre outras. E trabalhar com essas dimensões não significa transformá-las em conteúdos escolares ou temas transversais, mas ter a sensibilidade para perceber como esses processos constituintes da nossa formação humana se manifestam na nossa vida e no próprio cotidiano escolar.

Para que os profissionais da educação desenvolvam o entendimento acerca destas dimensões, destaca-se a necessidade de políticas públicas voltadas para a formação de todos os profissionais diante das relações étnico-raciais e para que se compreenda toda uma questão histórica que reflete em posturas de naturalização e continuidade de práticas racistas e preconceituosas que precisam mais que nunca serem cortadas pela raiz.

Para refletir sobre as relações étnico-raciais, cabe primeiramente compreender algumas definições, como a de raça, conforme propõe Santiago (2019, p. 306):

A raça é um elemento forjado historicamente para sustentar privilégios, os quais, quando construímos movimentos para pensar a branquitude, são evidenciados, seja pela reprodução estética contida nas histórias contadas às crianças pequenininhas, seja pelas ilustrações afixadas na creche, ou pelas posturas assumidas pelas docentes.

Segundo Quijano (2005), a ideia de raça passou a fazer sentido com a conquista da América, com as diferenças fenotípicas entre conquistadores e conquistados. Nas palavras desse autor, "[a] formação de relações sociais fundadas nessa ideia, produziu na América identidades sociais historicamente novas: índios, negros e mestiços, e redefiniu outras" (QUIJANO, 2005, p. 107). Assim, é importante também entender que a branquitude na sociedade é marcada pelo processo de hierarquização, em que a identidade branca tem como garantia privilégios simbólicos constituídos pelo poder estrutural.

Diante disso, Almeida (2019) define o racismo diante de três concepções. A primeira concepção, individual, uma espécie de anormalidade ou irracionalidade de fenômeno ético ou psicológico de caráter individual ou coletivo tem a discriminação manifestada de maneira direta a menosprezar e diminuir o outro. A segunda concepção, institucional, revela que o racismo não se resume a comportamentos individuais, mas é resultado do funcionamento das instituições (como o Estado, as instituições de ensino e as instituições religiosas), como uma máquina que de forma indireta confere privilégios ou desvantagens como pressuposto à raça, assim, as instituições moldam o comportamento humano diante de regras previamente estabelecidas pela estrutura social e sua manutenção depende da capacidade de grupos dominantes de institucionalizá-las. A segunda concepção é menos evidente que a primeira, porém não menos destrutiva. Já a terceira concepção, estrutural, se funda no racismo em decorrência da própria estrutura social, em que a normalização e naturalidade se compõem nas relações. As instituições são apenas a materialização dessa estrutura social, sendo estas racistas porque a própria sociedade é racista.

Considerando a educação infantil como uma instituição que corporifica este racismo estrutural, é relevante a discussão que este estudo se propõe a fazer como embasamento para práticas educativas antirracistas. Por isso, contatamos cinco instituições de ensino da PMF e a partir da abertura das instituições, um questionário foi enviado às profissionais de Educação Infantil. Até o momento de escrita deste artigo, nove profissionais responderam ao questionário. Dessas nove, três são auxiliares de sala, duas são professoras auxiliares e quatro são professoras. Sobre sua formação, três possuem graduação em Pedagogia, cinco, especialização e uma, mestrado. E em relação ao tempo de função, o intervalo está entre dois e trinta anos, com um tempo médio de 12 anos. É importante destacar que todos os nomes das participantes, 
respondentes do questionário, foram substituídos por nomes fictícios escolhidos por elas mesmas, seguindo os padrões éticos estabelecidos pelo Comitê de Ética na Pesquisa em Seres Humanos da Fundação Universidade Regional de Blumenau (FURB). A pesquisa que dá base a este artigo foi aprovada pelo Comitê de Ética, sob no 3.852 .941 em 21 de fevereiro de 2020. No que segue, apresentamos dados dos questionários respondidos por essas participantes.

Considerar que na Educação Infantil não existe racismo é desconhecer que as instituições educacionais estão atreladas ao racismo estrutural, que se enraíza e se estrutura nos sujeitos de forma tão naturalizada que não é percebido, o que pode ser evidenciado em algumas respostas ao questionário, diante das seguintes perguntas: "as crianças haitianas são vistas pelas demais crianças e pela comunidade educativa como diferentes? Qual sua opinião? Já ouviu algum tipo de comentário, qual?” e “já ocorreu alguma forma de discriminação/preconceito na sala entre os coleguinhas? Se ocorreu, como você administrou a situação? Por gentileza, narre com todos os detalhes possíveis que lembrar". Revelamos a seguir respostas das profissionais:

Nunca observei nenhum tipo de discriminação em sala com seus pares. (Excerto 1, resposta ao questionário, profissional Bianca).

Não, nunca percebi tratamento diferente. (Excerto 2, resposta ao questionário, profissional Suelen).

Não são vistas de maneira diferente. Minha opinião, é uma criança como as outras, cuido e educo, dou carinho e atenção, igual a todas as crianças. (Excerto 3, resposta ao questionário, profissional Emília).

Realizamos um trabalho forte para que isso não aconteça, felizmente não presenciei nada do tipo além do respeito seja para qual for à diferença que nos acompanhe. (Excerto 4, resposta ao questionário, profissional $\mathrm{Ni}$ ).

Em outras turmas existem os comentários da cor da pele, cabelo, ginga, vestimentas coloridas e outros. (Excerto 5, resposta ao questionário, profissional Professora).

Diante das respostas, cabe evidenciar que as profissionais Bianca, Suelen e Emília parecem negar a existência do racismo na Educação Infantil, vivendo, portanto, neste modo estruturante diante da institucionalização social do racismo posto de forma naturalizada no cotidiano escolar. Os profissionais como indivíduos sociais desta máquina engendrada tendem a fortalecer a visão eurocêntrica muitas vezes diante da negação e da falta de compreensão da existência do racismo, assim podem contribuir para sua legitimidade e continuidade. Já a profissional $\mathrm{Ni}$, ao dizer "realizamos um trabalho forte para que isso não aconteça", reconhece a existência do racismo perante a sociedade, porém ainda não o evidenciou no interior da instituição em que trabalha. E a profissional Professora, ao afirmar "em outras turmas existem", admite que o racismo existe e que tenha presenciado atitudes racistas em outras turmas, porém não na turma em que trabalha. $\mathrm{O}$ fato de o racismo não existir na turma, segundo Professora, não necessariamente quer dizer que o racismo inexista naquele contexto. Pode significar que o racismo não é percebido em gestos, olhares e atitudes, pois, nas palavras de Professora, ela nega a existência de "comentários da cor da pele, cabelo, ginga, vestimentas coloridas e outros", na linguagem verbal.

Esses excertos nos levam a refletir sobre como a escola pode propagar modelos. Nas palavras de Oliveira e Abramowicz (2010, p. 212),

[a] escola veicula, em conjunto com outros equipamentos centralizadores e difusores de sentido e de estética, entre eles a mídia, um modelo estético hegemônico, bem como um modelo de "saúde" que é veiculado e produzido incessantemente como o melhor, o único, o bonito e o que deve ser perseguido por todos.

Será que como profissionais da Educação propomos interações positivas de modo que se procure quebrar esta estética hegemônica do embranquecimento tão presente na sociedade e com isso, no ambiente escolar? Ou o afirmamos diante de práticas negativas de modo natural? 
Pensar nesta reflexão nos leva a afirmar que o preconceito e a discriminação muitas vezes se fazem ocultos, mas existem, estão lá para manter a dominação de certos grupos no poder e a opressão de outros. Refletindo sobre as respostas das profissionais nos excertos de número 1, 2 e 3 nos levam às palavras de Souza (2017, p. 195):

\begin{abstract}
Nota-se que a negação do racismo no contexto escolar também funciona como uma estratégia para a recusa à inclusão da temática nos currículos. Esta mudança, quando ocorre, tem sido pontual e paliativa, como uma ação para "resolver problemas de discriminação". Além disso, verifica-se que estes discursos envolvem o desafio de abertura docente para compreensão do racismo criado e recriado, cotidianamente, em nossa sociedade, e manifesto nas escolas durante o encontro entre sujeitos pertencentes a diferentes grupos sociais, culturais, religiosos: crianças, adolescentes, jovens, adultos, homens, mulheres, negros/ as, brancos/as, pobres e ricos, professores e professoras, equipes de apoio, gestores/as. Afirmar que não há racismo na escola engendra uma reflexão acerca das razões para a permanência de um discurso que, antes mesmo de compreender, conhecer, aproximar-se da realidade, nega-a.
\end{abstract}

Trabalhar pedagogicamente com as relações étnico-raciais e com a diversidade na Educação Infantil é pensar de forma ampla e em cada detalhe. Como exemplo, podemos citar as imagens de pessoas em murais espalhados pelas instituições (fotos e recortes de revistas com pessoas diversas), será que neles as imagens contemplam todas as crianças e suas diversidades? Nas palavras de Santiago (2019, p. 315), "[a]s representações afixadas nas paredes da instituição de educação infantil são expressões culturais localizadas e constroem espaços de significados que expressam as relações sociais e seus contextos históricos".

Nesse contexto, questionamentos surgem, como "será que nas festas com apresentações musicais ou teatrais as crianças negras possuem o mesmo protagonismo que as brancas?" (GOMES, 2005, p. 150). É emergente refletir sobre nossas atitudes e escolhas de modo a compreender esta estrutura social imposta e manipulada de modo natural em nós. Podem ocorrer fatos extremamente antiéticos para um profissional da educação diante de atitudes consideradas levianas levando à discriminação e ao preconceito contra essas crianças, que exigem intervenções pontuais enérgicas por parte da direção da instituição, como as que traz Gomes (2005b, p. 150):

[...] em nome de uma suposta autonomia, uma professora pode colocar uma criança negra para dançar com um pau de vassoura durante uma festa junina porque nenhum coleguinha queria dançar com um "negrinho". [...] A escola deve, por um acaso, em nome da "autonomia" de cada docente, permitir e ser conivente com o (a) professor(a) que permite que as meninas brancas chamem a colega negra de "negra do cabelo duro" ou "cabelo de bombril".

Posições como estas perpetuam ainda mais esta discriminação e preconceito arraigado em nossa sociedade. É importante também refletir quanto às histórias contadas para as crianças, nessas histórias quem são os príncipes e princesas? E quem representa os heróis ditos mocinhos e os bandidos? Ainda nos momentos em que a brincadeira na creche envolve o dia do salão de beleza, há pentes e cremes para cabelos negros como comumente há para cabelos lisos? Crianças negras e brancas são acolhidas da mesma forma com carinho, atenção, cuidados e colinho? Trabalhamos a cultura africana e afro-brasileira como herança e identidade do povo brasileiro com nossas crianças? E os brinquedos, as bonecas representam as características das crianças ou são bonecas idênticas com a única diferença de uma ser branca e a outra pintada de preto ou marrom sem as peculiaridades físicas subjetivas de cada indivíduo, como traços de nariz, boca e cabelo? Ou ainda simplesmente não há bonecas negras em nossas salas? Nas palavras de Santiago (2019, p. 321),

[a]s instituições de educação infantil no Brasil inúmeras vezes constituem um lugar hostil para as crianças negras pequenininhas, não possuindo artefatos culturais que contribuam para seu acolhimento, bem como são marcadas pelo racismo institucional presente em nossa sociedade. Paralelamente a esse processo, muitos dos aspectos relativos ao acolhimento das culturas africana e afro-brasileira, e a desconstrução do racismo institucional, não se fazem presentes no cotidiano das instituições. 
Gomes (2003) evidenciou em sua pesquisa, com depoimentos de entrevistados quanto a depreciação ao corpo negro e ao cabelo crespo, o que Santiago (2019) sustentou no trecho acima, que as instituições de educação são espaços tensos no processo de construção da identidade negra. Por isso, trabalhar as relações étnico-raciais nas instituições educativas é buscar a efetivação de metodologias e práticas pedagógicas que desconstruam preconceitos raciais, sendo a educação racial um desafio para instituições de educação no Brasil.

Nas instituições educativas, os negros podem ter suas identidades valorizadas ou estigmatizadas, dependendo de como sua cultura, história e estética são percebidas e concebidas na sociedade. Conforme Gomes (2003, p. 171),

[c] onstruir uma identidade negra positiva em uma sociedade que, historicamente, ensina ao negro, desde muito cedo, que para ser aceito é preciso negar-se a si mesmo, é um desafio enfrentado pelos negros brasileiros. Será que, na escola, estamos atentos a essa questão? Será que incorporamos essa realidade de maneira séria e responsável quando discutimos, nos processos de formação de professores, sobre a importância da diversidade cultural?

Acreditamos que o primeiro passo a ser trilhado para um trabalho com as relações étnico-raciais nas instituições educativas seja apresentar, discutir, refletir, debater o etnocentrismo e o embranquecimento, aspectos necessários para a compreensão de uma educação étnico-racial diante da formação de continuada de professores. Mas isso tem acontecido? Perguntamos no questionário às profissionais de educação infantil, "você percebe que a secretaria municipal e/ou a instituição oferece(m) formações? Caso positivo, comente sobre essas formações e suas expectativas". Esta pergunta conversaria com as demais perguntas no questionário em relação às crianças haitianas e como resposta, obtivemos retornos muito parecidos às perguntas apresentadas anteriormente:

Sobre este assunto, nunca ouvi falar. (Excerto 6, resposta ao questionário, profissional Cláudia).

Não recebi nenhuma formação. (Excerto 7, resposta ao questionário, profissional Ana Lia).

A secretaria municipal até oferece, porém, as vagas são limitadas. (Excerto 8, resposta ao questionário, profissional Camilla).

Não sei opinar, não tenho conhecimento. Mas creio que devem ter se atualizado nesse sentido, pois a demanda vem crescendo cada vez mais. (Excerto 9, resposta ao questionário, profissional Aninha).

Diante das respostas, é importante observar que a PMF juntamente com a Secretaria Municipal de Educação possui um documento norteador muito importante quanto ao trabalho com as relações étnico-raciais na Educação. Porém, a partir dos excertos 6 a 9, parece que as profissionais o desconhecem. E, portanto, é admirável a rede ter um documento tão relevante, entretanto, ele deve sair da gaveta e ser amplamente discutido com os profissionais da educação, no coletivo, por meio da oferta de momentos de formação para todos os profissionais envolvidos na educação, em todos os níveis. Aninha, no excerto 9 , destaca a necessidade de formação nessa área, já que percebe a lacuna na formação inicial e continuada e também reconhece a demanda emergente na unidade em que trabalha.

Como a primeira autora deste artigo é servidora da PMF e vivenciou esta experiência, quando em anos anteriores a 2020, a Diretoria de Educação Infantil juntamente com a Gerência de Formação Continuada ofertava algumas turmas de um curso sobre as relações étnico-raciais, porém com vagas limitadas, conforme explicitado também por Camilla no excerto 8. Assim, um número muito pequeno de profissionais do quadro, se comparado ao número total de profissionais, participava do curso e considera-se a carga horária muito reduzida tendo em vista as reflexões e os debates necessários para transformações nas relações étnico-raciais nas instituições educacionais. 
Nas palavras da própria matriz curricular para ERER, da Secretaria Municipal de Educação da PMF (2016, p. 22),

[p]recisamos (re)aprender sobre novas bases civilizatórias a estabelecer relações étnicas sem os impactos nocivos do racismo. Necessitamos (re)ver os conteúdos e nos preparar para as novas abordagens que reivindicam as classes populares e os sujeitos da escola. [...] A ERER é para todos e traz centralidade em torno de um sujeito e seus conteúdos como forma de equilibrar as relações sociais e étnicas na escola e, sobretudo, como forma de potencializar a formação de sujeitos que se compreendam iguais nas suas identidades específicas. [...] Não importa se os/as estudantes/as negros/as e indígenas estão ou não presentes fisicamente em nossas salas de aula. Suas histórias estarão! Não contamos a história de quem somos, sem contarmos a história de brancos, negros e indígenas e suas (co)relações. Portanto, entendemos que para quem organiza a educação, delimita suas concepções, elabora seu projeto político pedagógico e planeja suas atividades de ensino, as relações étnico-raciais devem ser elencadas entre aquelas que estruturam a sociedade e sendo assim, estarão presentes em nossas práticas pedagógicas e no nosso currículo escolar.

Diante desta constatação de um novo currículo escolar, Gomes (2012) ressalta que o direito à educação e a universalização da Educação Básica trouxeram para o espaço educativo sujeitos antes invisibilizados ou desconsiderados como sujeitos de conhecimentos, que consigo trazem suas subjetividades. Passa-se então a questionar os currículos colonizadores que são perpetuados no ambiente educativo. Nesta perspectiva, Gomes (2012, p. 100) destaca que

[é] nesse contexto que se encontra a demanda curricular de introdução obrigatória do ensino de História da África e das culturas afro-brasileiras nas escolas da educação básica. Ela exige mudança de práticas e descolonização dos currículos da educação básica e superior em relação à África e aos afro-brasileiros. Mudanças de representação e de práticas. Exige questionamento dos lugares de poder. Indaga a relação entre direitos e privilégios arraigada em nossa cultura política e educacional, em nossas escolas e na própria universidade.

Tratar da temática racial em instituições de educação infantil compreendendo a infância e seu desenvolvimento diante das interações sociais estabelecidas se faz relevante para pensar na importância de uma instituição pautada em práticas antirracistas e sem preconceitos face aos imigrantes oriundos de outros países assim como os sujeitos de outros estados em busca de oportunidades.

Assim, pensar na desconstrução de estereótipos que as interações em sociedade produzem e (re)produzem no interior dos ambientes educativos se faz emergente. Gomes (2003) salienta que nossa sociedade tem historicamente provocado os negros a negarem suas próprias identidades desde muito cedo. Neste tocante, nos perguntamos se as instituições de educação estão atentas a esta realidade e se discutem de maneira responsável práticas pedagógicas que valorizam a identidade dos diferentes grupos?

Para refletirmos sobre esta indagação, trazemos excertos das profissionais de Educação Infantil desta pesquisa quando questionadas sobre a história e as culturas das crianças e famílias haitianas que fazem parte das instituições de educação infantil em que trabalham:

Sabia pouca coisa antes da pandemia, acabei conhecendo um pouco mais após a pandemia, pois eles precisaram de ajuda. Então, conheci a casa deles, soube que o pai perdeu um dos dois empregos e que a mãe continua sem entender nosso idioma. [Sobre o Haiti:] Quase nada! (Excerto 10, resposta ao questionário, profissional Cláudia)

Conheço mais a mãe, o pai eu vi apenas uma vez. Não tive tempo para conhecer um pouco mais a família [...] com a pandemia as aulas foram suspensas. [Sobre o Haiti:] Sei que ele fica no Caribe e que a população é bem carente, que muitos estão saindo de lá para ter uma vida melhor. (Excerto 11, resposta ao questionário, profissional Camilla). 
Sim. A mãe e o pai estão separados. Percebe-se que a mãe fica preocupada quando o pai vai visitá-la. Observamos o jeito da criança: como brinca, como anda, como come... E assim vamos aprendendo o que ela gosta de fazer e comer. [Sobre o Haiti:] Muito pouco. (Excerto 12, resposta ao questionário, profissional Suelen).

Sim, conheço, a família não fala o português estão tentando aprender. No dia da entrevista com a família, foi a mãe e um tio da criança que fala português e haitiano. [Sobre o Haiti:] Sei que falam a língua crioula haitiana e em espanhol, mas tem famílias haitianas que falam o inglês, comigo falaram palavras básicas, yes, no. (Excerto 13, resposta ao questionário, profissional Emília).

Para conhecer melhor um grupo e sua identidade pensamos ser relevante conhecer o contexto familiar das crianças, suas histórias e culturas. Nos excertos 10 a 13, percebe-se que as profissionais de Educação Infantil procuraram conhecer um pouco sobre as crianças e suas famílias, auxiliando-as assim estas questões em sua prática pedagógica na conscientização e na valorização da identidade individual de todas as crianças, principalmente quando em um mesmo ambiente educativo culturas de países tão diferentes convivem simultaneamente. Acreditamos que para realmente valorizar a cultura do Haiti por meio de sua rica história e de seus hábitos e costumes, faz-se necessário que os profissionais conheçam mais a fundo o país e suas culturas. Quando pouco se sabe sobre um povo, acaba-se por homogeneizar comumente as crianças no ambiente educativo. Nesta perspectiva, Oliveira e Abramowicz (2010, p. 214) afirmam que

[n]a realidade, a escola brasileira funda-se na ideia de escola única e igual para todos, mantendo, de forma oculta, uma ética de indiferença em relação às diferenças, já que a convicção na qual ela se apoia é a de ser indiferente aos territórios, à cultura de origem das famílias, ou seja, há uma indiferença ao outro como fundamento da escola.

Todavia, ressalta-se a posição de Camilla quando menciona que "a população é bem carente, que muitos estão saindo de lá para ter uma vida melhor", demonstra interesse e um pouco mais de conhecimento que as colegas nos excertos 10, 12 e 13. Sabe-se que ainda é pouco, mas já dá esperanças de que possua um olhar mais sensível para esse povo tão sofrido que vem ao Brasil em busca de oportunidades de sobrevivência.

Pode parecer clichê afirmar que a raça humana tem por característica sua rica diversidade, que nossa identidade é composta por várias culturas e como elas não são fixas continuamos a constantemente nos compor com o outro e a nós mesmos pelas interações. Para Hall (2000, p. 109) é precisamente porque:

As identidades são construídas dentro e não fora do discurso que precisamos compreendê-las como produzidas em locais históricos e institucionais específicos, no interior de formações e práticas discursivas específicas, por estratégias e iniciativas específicas. Além disso elas imergem no interior do jogo de modalidades específicas de poder e são, assim, mais o produto da marcação da diferença e da exclusão do que o signo de uma identidade idêntica, naturalmente constituída de uma "identidade" em seu signo tradicional - isto é uma mesmidade que tudo inclui, uma identidade sem costuras, inteiriça, sem diferenciação interna.

Deste modo, a identidade deixa de ser algo imutável no mundo globalizado, fazendo surgir um indivíduo fragmentado (HALL, 2015). Assim, os indivíduos estão constantemente entrelaçados pela interação com outras regiões, outros povos, novas circunstâncias de condição social e, diante disso, cultural que lhe fazem parte integrante, sendo assim chamada de "crise de identidade", vista como parte de um processo de mudanças em sociedade. Hall $(2015$, p. 9) ainda esclarece que identidades culturais são "aqueles aspectos de nossas identidades que surgem de nosso 'pertencimento' a culturas étnicas, raciais, linguísticas, religiosas, e, acima de tudo nacionais". Diante disso, Gomes (2005a) destaca que a identidade é o resultado das relações de referências culturais que se estabelecem na linguagem, em rituais, na alimentação, nas tradições e em demais predicados que marcam a condição humana.

Diante dessas questões, refletir sobre a construção da identidade étnico-racial na educação infantil se faz necessário primeiramente analisar os padrões de humanidade espelhados pela sociedade que reverberam no cotidiano das instituições, assim como também compreender que em nossa prática pedagógica 
a diversidade precisa ser vislumbrada como riqueza e a nossa identidade como grandeza que só nós temos. Valorizar as diferenças e acolhê-las de forma positiva com oportunidades de interações de qualidade é o maior legado que instituições educativas infantis podem deixar aos nossos pequenos.

\section{Últimas reflexões}

"A educação é a arma mais poderosa que você pode usar para mudar o mundo."

Nelson Mandela

Sendo a Educação o caminho para a transformação, a instituição de Educação Infantil se mostra um mecanismo essencial neste processo como único espaço de educação formal em que a criança está inserida. Assim, configura-se como um relevante espaço de interações permeado por relações pedagógicas intencionalmente planejadas por profissionais capacitados para propiciar experiências para o desenvolvimento integral das crianças, além de ser um local de muita diversidade, como: cor, raça, etnia, gênero e pluralismo cultural, as quais as crianças desde muito cedo vão conhecendo e interagindo de forma a conceber posturas de respeito, valorização às diferenças, amor ao próximo ou o inverso, infelizmente dependendo das concepções e posturas presentes no interior dessas instituições, como o racismo, preconceito face ao imigrante e a negação do eu e do outro diante das opressões.

As instituições são o espelho da sociedade e os indivíduos o reflexo de suas interações. Ao adentrarem as instituições de Educação Infantil, as crianças trazem consigo vivências de relações familiares e vinculadas ao seio familiar, que reverberam nas instituições. Mas pensar no trabalho pedagógico com as relações étnico-raciais é ir além do conhecimento empírico, compreender o histórico e o social que nos circundam e por meio de práticas exitosas buscar a transformação do que está posto. Para tanto, a formação inicial e continuada dos profissionais de Educação se faz mais que necessária, no contexto deste estudo, a formação de profissionais em serviço diante da temática em reflexão que carece de maior envolvimento, auxílio e suporte da Secretaria Municipal de Educação. Assim como os dados desta pesquisa revelaram a percepção das profissionais, também ressaltaram a compreensão por parte delas acerca da importância e necessidade de uma maior preparação para o trabalho com as relações étnico-raciais já que elas evidenciam esta demanda nas instituições em que atuam.

Além da apresentação de um recorte de uma pesquisa de mestrado em andamento, este artigo é resultado também de uma autorreflexão das autoras, pois como pedagoga que trabalha na Educação Infantil e professora atuante no Ensino Universitário, conseguimos nos perceber como peças desta máquina movida pelas interações sociais e pela sociedade nos moldando ao padrão eurocêntrico. Refletir sobre nossas práticas é fundamental para modificar certas posturas de naturalização e assim perceber os diferentes processos históricos que resultaram nas diferenças em desigualdades de raciais.

A negação da existência do racismo no interior das instituições pelos profissionais de Educação reforça o privilégio imposto pela colonialidade de maneira oculta e silenciosa. Desta forma, práticas educativas que vão ao encontro dessa perspectiva de negação normalmente propiciam às crianças somente o contato com determinadas histórias e estilos estéticos, desconsiderando a forma de educar para as relações étnico-raciais. E assim, ressalta-se a importância de se refletir sobre esta relação institucional etnocêntrica. As relações étnico-raciais nas instituições educativas só serão transformadas se houver diálogo, reflexão e muita discussão, que podem partir de estudos como o apresentado neste artigo. 


\section{Referências}

ALMEIDA, Silvio. Racismo estrutural. São Paulo: Pólen, 2019.

ALPHONSE, Fritznel; MACEDO, José Rivair. O Programa pró-Haiti nas universidades públicas brasileiras (2011-2016). Temáticas, Campinas, v. 25, n. 49/50, p. 233-270, fev./dez. 2017.

BRASIL. Lei n ${ }^{\circ} 8.069$, de 13 de julho de 1990. Dispõe sobre o Estatuto da Criança e do Adolescente e dá outras providências. Diário Oficial da União: seção 1, Brasília, DF, p. 13563, 16 jul. 1990. Disponível em: http://www.planalto.gov.br/ccivil_03/ leis/18069.htm. Acesso em: 13 ago. 2020.

BRASIL. Lei n ${ }^{\circ}$ 9.394, de 20 de dezembro de 1996. Estabelece as diretrizes e bases da educação nacional. Diário Oficial da União: seção 1, Brasília, DF, p. 27833, 23 dez. 1996. Disponível em: http://www.planalto.gov.br/ccivil_03/leis/19394.htm. Acesso em: 22 jun. 2020.

CARVALHO, José Carlos de Paula. Etnocentrismo: inconsciente, imaginário e preconceito no universo das organizações educativas. Interface, Botucatu, v. 1, n. 1, ago. 1997. Disponível em: https://www.scielosp. org/pdf/icse/1997. vln1/181-186/pt. Acesso em: 16 set. 2020.

FERNANDES, Duval; CASTRO, Maria da Consolação Gomes; RIBEIRO, Carolina. Migração Haitiana para o Brasil: Minas Gerais como destino, a fala dos haitianos. In: SEMINÁRIO SOBRE A ECONOMIA MINEIRA, 16., 2014, Diamantina. Anais [...]. Belo Horizonte: UFMG/Cedeplar, 2014.

FREIRE, Paulo. A Educação na Cidade. São Paulo: Cortez, 1991.

GOMES, Nilma Lino. Educação, identidade negra e formação de professores/as: um olhar sobre o corpo negro e o cabelo crespo. Educação e Pesquisa, São Paulo, v. 29, n. 1, p. 167-182, jan./jun. 2003.

GOMES, Nilma Lino. Educação e relações raciais: refletindo sobre algumas estratégias de atuação. In: MUNANGA, Kabengele (org.). Superando o Racismo na escola. 2. ed. Brasília, DF: MEC/Secadi, 2005. p.143-154.

GOMES, Nilma Lino. Relações étnico-raciais, educação e descolonização dos currículos. Currículo sem Fronteiras, Portugal, v. 12, n. 1, p. 98-109, jan./abr. 2012.

GOMES, Marcela Andrade. Os impactos subjetivos dos fluxos migratórios: os haitianos em Florianópolis (SC). Psicologia \& Sociedade, Belo Horizonte, v. 29, e162484, dez. 2017. Disponível em: https://www.scielo.br/pdf/psoc/ v29/1807-0310-psoc-29-e162484.pdf. Acesso em: 3 set. 2020.

HALL, Stuart. Quem precisa da identidade? In: SILVA, Tomaz Tadeu. Identidade e diferença: a perspectiva dos estudos culturais. Petrópolis: Vozes, 2000. p. 103-133.

HALL, Stuart. A identidade cultural na pós-modernidade. Rio de Janeiro: Lamparina, 2015.

KRAMER, Sonia. Infância, Cultura Contemporânea e Educação Contra a Barbárie. Revista Teias, Rio de Janeiro, v. 1, n. 2, p. 1-14, ago. 2007. Disponível em: https://www.e-publicacoes.uerj.br/index.php/revistateias/article/viewFile/23857/16830. Acesso em: 6 ago. 2020.

MAGALHÃES, Luís Felipe Aires. O Haiti é Aqui: sub imperialismo brasileiro e imigrantes haitianos em Santa Catarina - SC. Revista Brasileira de Estudos Latino-Americanos, Florianópolis, v. 5, n. 1, jan./mar. 2015.

MAGALHÃES, Luís Felipe Aires; BAENINGER, Rosana. Trabalhadores Imigrantes: haitianos e haitianas em Santa Catarina - SC. In: CONGRESO DE LA ASOCIACIÓN LATINOAMERICANA DE POBLÁCION, 7.; ENCONTRO NACIONAL DE ESTUDOS POPULACIONAIS, 20., 2016, Foz do Iguaçu. Anais [...]. Rio de Janeiro: ABEP, 2016.

MOTTA, Flavia; PAULA, Claudemir de. Questões Raciais para Crianças: resistência e denúncia do não dito. Educação \& Realidade, Porto Alegre, v. 44, n. 2, e88365, 2019. Disponível em: https://www.scielo.br/pdf/edreal/v44n2/2175-6236edreal-44-02-e88365.pdf. Acesso em: 22 jun. 2020.

OLIVEIRA, Fabiana de; ABRAMOWICZ, Anete. Infância, raça e "paparicação". Educação em Revista, Belo Horizonte, v. 26, n. 2, p. 209-226, ago. 2010. Disponível em: https://www.scielo.br/pdf/edur/v26n2/a10v26n2.pdf. Acesso em: 22 jun. 2020.

PINTO, Manuel. A infância como construção social. In: PINTO, Manuel; SARMENTO, Manuel Jacinto (coord.). As crianças: contextos e identidades. Braga: CIEC/UM, 1997. p. 33-73.

PREFEITURA MUNICIPAL DE FLORIANÓPOLIS (PMF). Secretaria Municipal de Educação. Matriz Curricular para Educação das Relações Étnico-Raciais na Educação Básica. Florianópolis: CGP SOLUTIONS, 2016. Disponível em: http://www.pmf.sc.gov.br/arquivos/arquivos/pdf/27_09_2019_7.20.09.e37692d403fcdcd97a84c5c7aa507172.pdf. Acesso em: 22 jun. 2020. 
QUIJANO, Aníbal. Colonialidade do poder, eurocentrismo e América Latina. In: LANDER, Edgardo (org.). A colonialidade do saber: eurocentrismo e ciências sociais - perspectivas latino-americanas. Buenos Aires: CLACSO, 2005. p. 107-130.

RIBEIRO, Carlos Antonio Costa. Contínuo racial, mobilidade e "embranquecimento". Revista Brasileira de Ciências Sociais, São Paulo, v. 32, n. 95, e329503, 2017. Disponível em: https://www.scielo.br/pdf/rbcsoc/v32n95/0102-6909rbcsoc-3295032017.pdf. Acesso em: 16 set. 2020.

SANTA CATARINA. Decreto n 509, de 17 de março de 2020. Dá continuidade à adoção progressiva de medidas de prevenção e combate ao contágio pelo coronavírus (COVID-19) nos órgãos e nas entidades da Administração Pública Estadual Direta e Indireta e estabelece outras providências. Diário Oficial do Estado de Santa Catarina: Poder Executivo, Florianópolis, ano 86, n. 21.223-A, p. 1, 17 mar. 2020a.

SANTA CATARINA. Decreto ${ }^{\circ}$ 724, de 17 de julho de 2020. Altera o Decreto $n^{\circ} 562$, de 2020, que declara estado de calamidade pública em todo o território catarinense, nos termos do COBRADE $\mathrm{n}^{\circ}$ 1.5.1.1.0 - doenças infecciosas virais, para fins de enfrentamento à COVID-19, e estabelece outras providências. Diário Oficial do Estado de Santa Catarina: Poder Executivo, Florianópolis, ano 86, n. 21.312, p. 1, 17 jul. 2020b.

SANTIAGO, Flávio. Branquitude e creche: inquietações de um pesquisador branco. Educar em Revista, Curitiba, v. 35, n. 76, p. 305-330, ago. 2019. Disponível em: https://revistas.ufpr.br/educar/article/view/66099/39566. Acesso em: 22 jun. 2020.

SARMENTO, Manuel Jacinto. Gerações e alteridade: interrogações a partir da sociologia da infância. Educação \& Sociedade, Campinas, v. 26, n. 91, p. 361-378, maio/ago. 2005. Disponível em: https://www.scielo.br/pdf/es/v26n91/ a03v2691.pdf. Acesso em: 4 ago. 2020.

SOUZA, Márcia Lúcia Anacleto de. "Lá na escola (não) tem racismo!": reflexões sobre experiências formativas em educação para as relações étnico-raciais. Revista Ensino Interdisciplinar, Mossoró, v. 3, n. 8, p. 193-209, maio 2017. Disponível em: http://periodicos.uern.br/index.php/RECEI/article/view/2302/1228. Acesso em: 22 jun. 2020.

Data de submissão: 15/08/2020

Data de aceite: $21 / 09 / 2020$ 